\title{
La formación docente como una condición esencial para el éxito en el desarrollo de la escritura en el aula*
}

\section{Teacher Education as an Essential Condition for Success in the Development of Writing in the Classroom}

\section{Cristina Rosales Guacales, Yuly Andrea Murcia, Lina Rodríguez Ramírez y Sandra Díaz Rojas***}

Aprender a escribir bien requiere de una instrucción formal que dura muchos años y que quizás no termina nunca

Daniel Cassany

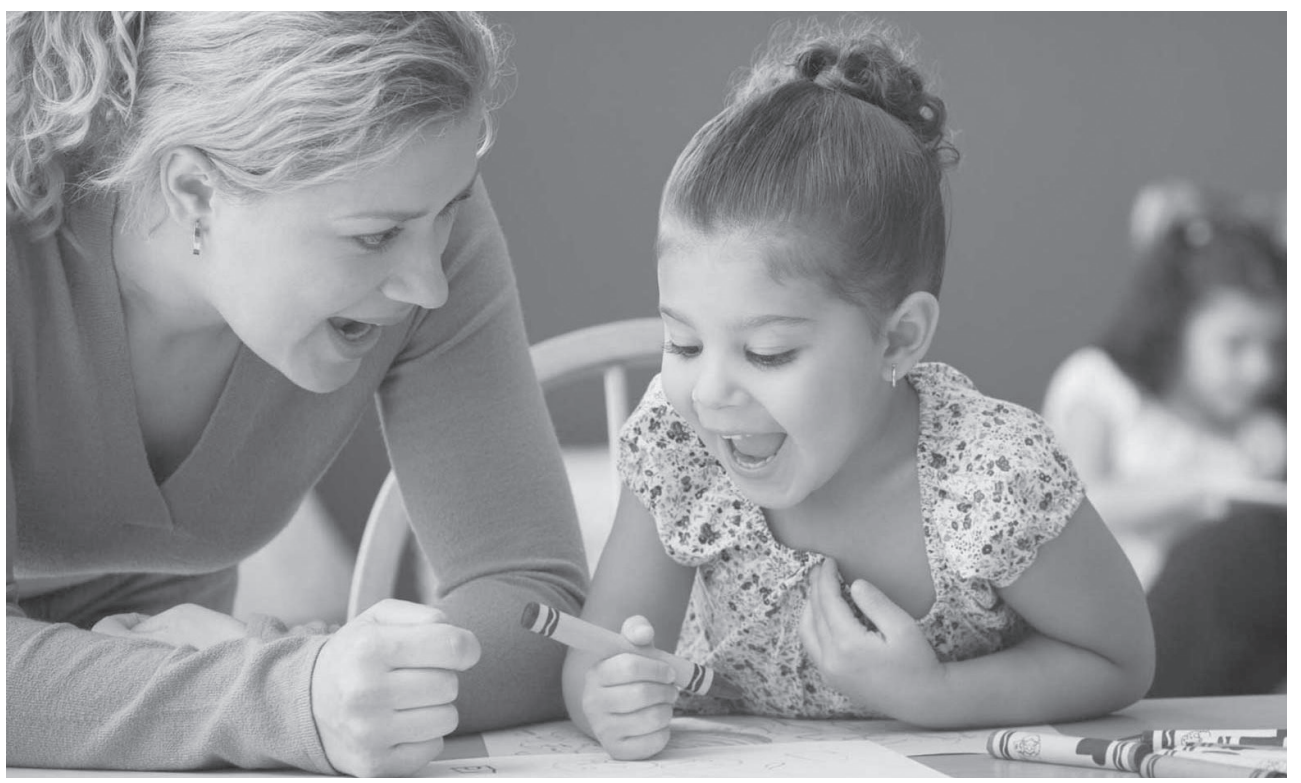

Citar este artículo como: Rosales Guacales, C., Murcia, Y. A., Rodríguez Ramírez, L. y Díaz Rojas, S. (2017). La formación docente como una condición esencial para el éxito en el desarrollo de la escritura en el aula. Revista Papeles, 9(17), 57-68.

Fecha de recibido: octubre 5 de 2016.

Fecha de aceptación: febrero 10 de 2017.

* Artículo basado en la tesis de grado análoga en la Especialización en Didácticas para Lecturas y Escrituras con énfasis en Literatura de la Universidad de San Buenaventura, bajo la dirección del profesor Enrique FerrerCorredor.

* Estudiantes de la Universidad de San Buenaventura de Bogotá. Correos electrónicos: Cristina Rosales: crirog77@hotmail.com, Andrea Murcia: andreamure@hotmail.com, Lina Rodríguez: linarodriguez201@gmail. com, Sandra Díaz Rojas: sanddiaz2005@gmail.com 


\title{
Resumen
}

El presente artículo deriva de un ejercicio de diagnóstico de la labor realizada por cinco docentes de lengua castellana de quinto grado de educación básica primaria en cinco colegios de diferentes estratos socioeconómicos en la ciudad de Bogotá. Para tal efecto, se elaboraron tres matrices para analizar: planeaciones de clase, cuadernos y trabajos de producción escrita en un periodo académico, que permitieron determinar en qué medida las competencias disciplinares y pedagógicas puestas en juego por los docentes incidieron en el desarrollo de los procesos escriturales de sus estudiantes.

Palabras clave: labor docente, competencias, escritura, competencia disciplinar, competencia pedagógica, proceso, desarrollo.

\begin{abstract}
This article is derived from a diagnostic exercise of the performance of five teachers of Spanish language in fifth level of elementary school in five schools of different socio-economic status. To this aim three matrices were developed to analyze class planners, notebooks and written tasks in an academical term, in order to determine to what extent the disciplinary and pedagogical competences performed by teachers influenced the development of the writing process of their students.
\end{abstract}

Key words: teacher performance, pedagogical competence, disciplinar competence, writing, process, development.

\section{Introducción}

Muchos proyectos educativos que se generan en Colombia actualmente buscan promover el desarrollo de las competencias en lectura y escritura de los estudiantes en todo el país. Aunque hay mucho por hacer a este respecto, es claro que iniciativas institucionales particulares han alcanzado logros significativos; no obstante, el camino por recorrer plantea desafíos que requieren de la participación decidida de los docentes: principales actores en este proceso. En este sentido surge la pregunta: ¿cómo los aciertos o las fallas en que estamos incurriendo los docentes de lengua castellana al momento de desarrollar competencias inciden en el proceso de escritura en nuestros estudiantes?

Así, una de las problemáticas que más se revela en torno al proceso de escritura es que al llegar a básica secundaria los estudiantes no han desarrollado con suficiencia las habilidades y competencias que debieron desarrollar en los grados anteriores, o eso expresan sus docentes. De igual forma, esto se revela en los resultados de las Pruebas Saber y las pruebas PISA. Lo mismo sucede en la transición de la educación media vocacional a la universidad, en la que los docentes manifiestan su preocupación frente a la competencia de escritura con la que los estudiantes deberían llegar a esta etapa de su formación.

Esto nos preocupa en la medida en que la escritura, atendiendo a los contextos en que se produzca, demanda de unos mínimos a nivel de contenido y de forma que den cuenta del nivel de competencia de los docentes de lengua castellana en el desarrollo de dichas competencias.

Esta investigación se realizó en el transcurso de la Especialización en Didácticas para 
Lecturas y Escrituras con énfasis en Literatura que ofrece la Universidad de San Buenaventura, en función de determinar cómo inciden las competencias disciplinares y pedagógicas de algunos docentes de lengua castellana de diferentes colegios en la ciudad de Bogotá en el desarrollo de las competencias de escritura de sus estudiantes. Esta investigación, aunque se desarrolló en un lapso breve, reveló parte de lo que está sucediendo actualmente en las aulas de lengua castellana. Su utilidad radica en que puede servir tanto a las autoras de la investigación como a los docentes interesados en el tema, para reflexionar en torno a lo que está pasando en el aula, lo que nos falta por hacer o implementar en aras de contribuir al desarrollo de competencias necesarias en procesos de escritura efectivos.
El objetivo general de nuestra investigación fue: hacer evidente cómo las competencias disciplinares y pedagógicas de los docentes de lengua castellana inciden en el desarrollo de las competencias requeridas en los procesos de escritura en estudiantes de quinto grado, en un periodo académico, en unas aulas de colegios de Bogotá de diferentes estratos socioeconómicos. Para tal efecto, analizamos: planeaciones de clase, cuadernos de los estudiantes y trabajos de producción escrita, valiéndonos de instrumentos que diseñamos y que nos permitieron establecer la pertinencia y eficacia de las estrategias utilizadas por los docentes y de los saberes puestos en juego en el desarrollo de las competencias escriturales de sus estudiantes de quinto grado de educación básica primaria.

\section{Fases del proceso}

\section{Documentación}

En tanto se delimitó el problema, procedimos a documentarnos, apoyándonos en teorías y postulados de la pedagogía y la filología, en tanto constituyen los saberes mínimos deseables para el desempeño cabal de la labor del docente que tiene la responsabilidad de guiar, en este caso concreto, el desarrollo de procesos de escritura. De igual manera, recurrimos al documento rector del área, a los Estándares básicos de Competencias del lenguaje, propuestos por el Ministerio de Educación Nacional. Acudimos a Gastón Bachelard para encauzar nuestra investigación desde sus planteamientos en torno a los obstáculos epistemológicos para llegar al conocimiento y al conocimiento científico. Julián de Zubíría fue referente en cuanto aportó, desde su modelo pedagógico dialogante, la idea de la necesidad de que los docentes creemos estrategias y ambientes en los que nuestros estudiantes puedan desarrollarse de manera integral. Por su parte, Flórez Ochoa contribuyó con sus nociones de pedagogía y enseñabilidad; de Camilloni tomamos su perspectiva sobre el saber didáctico/erudito como disciplina teórica. También nos apoyamos en Cassany, en torno a la necesidad de una didáctica específica en el proceso de escritura; en Flower y Hayes para fundamentar lo relativo al proceso cognitivo implicado en el proceso de escritura; y por último recurrimos a Teun van Dijk en lo relacionado con la textualización y sus condiciones: coherencia y conectividad.

\section{Diseño de matrices}

Para comenzar, se determinaron las categorías a observar y analizar en cada instrumento (primera matriz). Se continuó con la revisión y análisis de las planeaciones de clase, atendiendo a las categorías propuestas para la observación: estándares, contenidos, objetivo general, objetivos específicos, actividades, evaluación, tiempo, recursos (segunda matriz). Se continuó con los cuadernos, observando: estándares, contenidos, objetivo general, objetivo específico, logros, actividades, retroalimentación. En la tercera matriz se registraron las producciones escritas para determinar si 
el(los) ejercicio(s) propuesto: explicitaba la tipología a realizar, tenía la superestructura correspondiente a la tipología, desarrollaba un tema a través de una idea principal, era coherente, usaba algún mecanismo de cohesión, era retroalimentado desde la tipología textual, contribuía al desarrollo de la creatividad, contribuía al desarrollo de competencias en escritura, y si se desarrolló siguiendo una metodología. Se continuó estableciendo una comparación general para cada instrumento, base de las conclusiones a las que llegamos.

\section{Análisis de los insumnos}

En esta parte del proceso analizamos las planeaciones de clase de cada uno de los docentes que constituía la muestra y los cuadernos de diez estudiantes de cada colegio: tres de los más sobresalientes, cuatro de los de desempeño promedio y tres de los de bajo rendimiento; y trabajos de producción escrita propuestos en el periodo correspondiente analizado. Cabe anotar que en dos de los colegios observados se tomaron las muestras del primer periodo académico, y en los otros tres colegios del segundo.

A continuación procedimos a realizar un análisis comparativo de los insumos que arrojó los siguientes resultados.

\section{Análisis comparativo de la planeación}

Los Estándares Básicos de competencias de Lenguaje planteados por el MEN (2006) no aparecen referenciados de manera explícita en ninguna de las planeaciones de los colegios observados. Hay, en su lugar, un intento de abordar diferentes tipologías textuales como: cartas, cuentos, biografías, etc.; cabe mencionar que el colegio 05 no trabaja ninguna tipología, solo se les pide a los estudiantes hacer transcripciones, copias de textos y resúmenes.

Es una constante el abordaje de temáticas relacionadas con categorías gramaticales o aspectos gramaticales generales; no obstante, no hay actividades que refuercen estas temáticas o se trabajen en contexto, como lo sugieren los estándares. Es importante anotar que, en tres de los cinco colegios, las actividades de lecturas que se realizan a partir del plan lector son el fundamento para ejercicios de escritura que no logran trascender un proceso.

Cabe destacar que todos los colegios realizan una prueba diagnóstica al inicio del año; sin embargo, esta no es tenida en cuenta en la planeación para el desarrollo de las temáticas a abordar en el proceso de escritura. En este sentido, Cassany (1989) es enfático al sugerir que el diseño curricular, en consecuencia la planeación, debe considerar o contemplar los resultados arrojados por este tipo de prueba, y de allí partir para la implementación y fortalecimiento del proceso de escritura.

Excepto en el colegio 03, los demás colegios no plantean objetivos generales, ni específicos, ni logros; no obstante, las actividades que se plantean están apuntando implícitamente al desarrollo de lo que Cassany (1989) llama el nivel funcional e instrumental dentro de los procesos de escritura. Así, refiriéndonos al primer nivel, en las planeaciones de todos los colegios se proponen actividades con las que se pretende fortalecer la comunicación interpersonal y dar cuenta del uso apropiado de la lengua en los contextos en que aparecen los diferentes ejercicios de escritura. El nivel instrumental, que implica recurrir a la lectura como punto de partida para la escritura, se trabaja en los Colegios 02, 03 y 05. Sin embargo, insistimos en que no hay evidencia de proceso al momento de encarar la escritura; en su lugar, se propone ejecutar tareas de manera aislada.

En cuanto a la evaluación, los colegios 02 y 03 plantean evaluación formativa y sumativa, pero no especifican los criterios a evaluar en cada una. Los colegios 04 y 05 en su formato de planeación no contemplan la evaluación, mientras que el colegio 01 no hace planeación. 
En relación con el aspecto tiempo, hay evidencia de conciencia frente a él para el desarrollo de las diferentes temáticas; sin embargo, desde Cassany (1989) y Flower y Hayes (1996), y en lo relativo específicamente al proceso de escritura, el cual supone un proceso que pasa por diferentes momentos, se evidencia que este no se refleja en el desarrollo de las diferentes actividades escriturales.

\section{Análisis comparativo de los cuadernos}

En los cuadernos de los diferentes colegios observados no se explicitan los estándares; sin embargo, se infiere que son trabajados de diferentes maneras y, en el caso particular de los relativos a la producción textual, todos los colegios abordan la producción de diferentes tipos de textos, algunos con más detalle que otros; no obstante, en lo relacionado con el estándar que propone seguir un proceso en la producción textual ninguno de los casos observados da cuenta de ello.

Respecto a los contenidos, todos los colegios analizados abordan temáticas relacionadas con temas gramaticales o literarios, específicamente la narrativa. En este sentido, llama la atención que los temas gramaticales que podrían constituirse en un punto de partida para el desarrollo de un proceso escritural riguroso se trabaje de manera desarticulada, sin un antecedente, ni un consecuente.

En lo relativo a los objetivos, aparecen explícitos los objetivos específicos en el colegio 03, mientras que en los colegios 01 y 05 los objetivos podrían corresponder con los llamados desempeños e indicadores de logro respectivamente. Cabe anotar que en el colegio 01 se sugiere un desempeño en términos de proceso de escritura; en los demás colegios, tanto los objetivos como los logros están referidos en términos de identificar y reconocer, por ejemplo, tipologías narrativas, o características del cuento, la leyenda, o el mito.

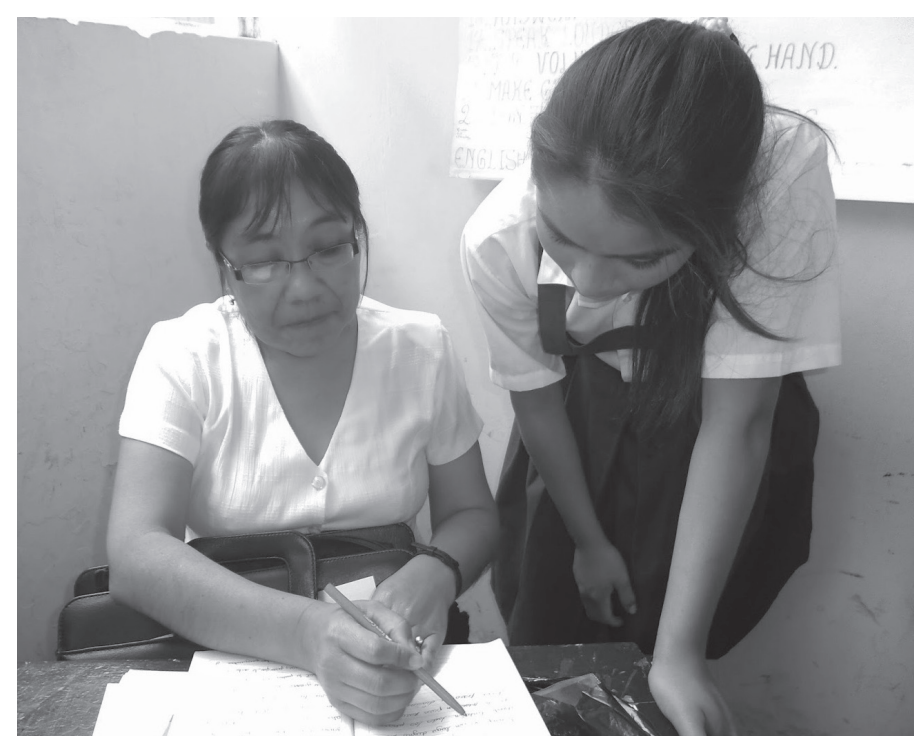

Las actividades propuestas en los colegios 02 y 03 son variadas, mientras que en los colegios 01, 04 y 05 siguen cada uno un patrón, por ejemplo: leer cualquier tipo de texto, llámese cuento o fábula; hacer un resumen o síntesis, o dado el caso, inventar o crear una historia o cuento de ese tipo de texto.

Esto lleva a concluir que las actividades que se proponen no promueven ni apoyan el desarrollo de procesos escriturales. En ese orden de ideas, la retroalimentación que realizan los diferentes profesores tampoco contribuye con el mismo, en tanto lo limitado de su alcance; pues una corrección ortográfica es apenas el comienzo de una buena retroalimentación que debería considerar, antes que aspectos formales, los relacionados con los contenidos, con el desarrollo y claridad en la exposición de las ideas

\section{Análisis comparativo de trabajos de producción escrita}

Los diferentes trabajos de producción escrita realizados en los cinco colegios observados proponen de manera muy limitada el abordaje de diferentes tipologías. Particularmente, el colegio 01, aunque pide realizar diferentes tipos de textos como anécdota, cuento, 
Tabla 1. Síntesis de los trabajos escritos

\begin{tabular}{|c|c|c|c|c|c|c|c|}
\hline & \multirow{2}{*}{ 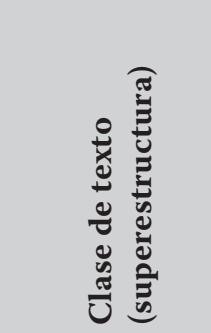 } & \multirow{2}{*}{ 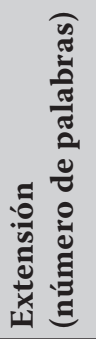 } & \multirow{2}{*}{ 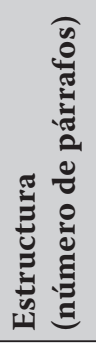 } & \multirow{2}{*}{ } & \multicolumn{3}{|c|}{$\begin{array}{l}\text { Mecanismos de cohesión } \\
\text { (conectividad) }\end{array}$} \\
\hline & & & & & Uso & Cantidad & Conectores usados \\
\hline Colegio 01 & $\begin{array}{l}\text { anécdota } \\
\text { cuento } \\
\text { fábula leyenda }\end{array}$ & 240 & 6 & Sí & Sí & 2 & $\begin{array}{l}\text { luego } \\
\text { cuando }\end{array}$ \\
\hline Colegio 02 & biografía & 240 & 4 & Sí & Sí & 5 & $\begin{array}{l}\text { pero } \\
\text { lo cual } \\
\text { la cual }\end{array}$ \\
\hline Colegio 03 & cuento & 140 & 3 & Sí & Sí & 2 & $\begin{array}{l}\text { porque } \\
\text { pero }\end{array}$ \\
\hline Colegio 04 & resumen & 260 & 6 & Sí & Sí & 3 & $\begin{array}{l}\text { cuando } \\
\text { pero entonces }\end{array}$ \\
\hline Colegio 05 & mito & 82 & 1 & Sí & No & & \\
\hline
\end{tabular}

Fuente: elaboración propia

fábula, leyenda, no muestra un tratamiento riguroso de la tipología narrativa, que supondríamos debería ser trabajada de alguna manera como antecedente del ejercicio de creación. La teoría se limita a una definición y caracterización muy básicas de las mismas, que se reducen a unas pocas líneas escritas en el cuaderno. El colegio 02 propone la elaboración de una biografía y varios resúmenes basados en unos capítulos del plan lector. $\mathrm{Al}$ respecto, cabe anotar que tampoco hay un tratamiento teórico previo a la elaboración de los trabajos escritos pedidos, ni hay evidencia de proceso. El colegio 03 pide elaborar dos cuentos como actividad complementaria del tema correspondiente al género narrativo y sus características; es importante mencionar que en los cuentos se evidencia la superestructura correspondiente, aunque limitado en el desarrollo de la trama. El colegio 04 solo trabajó dos resúmenes basados en las obras del plan lector; de igual manera, no se verifica previamente el tratamiento del tema alusivo a la elaboración de los mismos, y mucho menos se da cuenta de un proceso. En el colegio 05 no hay evidencia de elaboración de ningún tipo de texto. Las actividades relacionadas con el proceso de producción de textos escritos se limitan a la transcripción de diferentes tipologías.

Los trabajos escritos realizados por los estudiantes en las muestras analizadas, en general, dan cuenta del desarrollo de un tema; en ese mismo sentido, hay evidencia de coherencia temática; no obstante, a nivel de cohesión, o de conectividad como le llama van Dijk (1996), es demasiado limitado el uso de estos mecanismos, pues estos resultan básicos y elementales. Los muy pocos que allí aparecen, destacan, por ejemplo: entonces, porque, pero, luego; y estos corresponden más al uso cotidiano de la lengua que al uso formal que exige el texto escrito. La retroalimentación que realizan los profesores de los cinco colegios, sin excepción, se limita a la corrección ortográfica o a observaciones relativas a la caligrafía o a la presentación de los ejercicios; todas las observaciones son del orden formal, no del contenido, no hay una sola observación relativa a: tipología textual, coherencia o cohesión. 
En relación con la promoción de la creatividad, resulta importante destacar que solo el colegio 01 propone una actividad creativa en la que se les pide a los estudiantes inventar un cuento a partir de diez palabras que ellos eligen. En este sentido, cabe anotar, siguiendo a Cassany, que hay una suerte de consideración manifiesta en relación con los intereses o gustos de los estudiantes. Los trabajos y actividades planteados por los demás profesores brillan por su falta de creatividad; incluso alguno de ellos está muy desenfocado en su planteamiento: "elaborar un mito a partir de nombres de personajes", lo que no resulta una instrucción significativa, en cuanto no aporta una característica específica del género, no direcciona el tipo de texto que el estudiante debe elaborar. En su lugar, se debería haber propuesto una instrucción del tipo: inventar una historia relacionada con el origen de tu animal favorito, de tu fruta favorita, etc.; destacando la palabra en negrilla, pues de entrada sugiere la relación directa con la tipología. En este mismo sentido, la escasa promoción de la creatividad, en palabras de Zubiría (2006), estaría segregando una de las dimensiones que debemos desarrollar en nuestros estudiantes: la afectividad. En los diferentes trabajos de escritura propuestos, los profesores no promovieron de manera intencionada la creatividad, ni el desarrollo cognitivo. Así, entonces, al obviar este tipo de ejercicio, como ocurrió en el colegio 02 o en el 04, los profesores desaprovecharon una herramienta infalible, no solo en la promoción de la creatividad, sino en la construcción de identidad: en la elaboración de textos creativos hay un escenario efectivo, también, para el desarrollo tanto de la afectividad, en cuanto el estudiante puede crear mundos posibles a través de seres de papel que se interrelacionan, como el de la escritura; si los profesores no propician esos espacios, no favorecen el desarrollo de ninguna de las dos.

\section{Categorización poblacional}

El corpus de la muestra para esta investigación lo conformaron cinco colegios ubicados en Bogotá, pertenecientes a diferentes clases sociales.

Tabla 2. Perfiles de los colegios observados

\begin{tabular}{|c|c|c|c|c|c|}
\hline & Colegio 01 & Colegio 02 & Colegio 03 & Colegio 04 & Colegio 05 \\
\hline Estrato & 3 & 6 & $2-3$ & $2-3$ & $3-4$ \\
\hline Modalidad & Privado & Privado & Privado & Público & Privado \\
\hline Jornada & Única & Única & Única & Mañana & Única \\
\hline Nivel ICFES & N/A & Muy superior & Alto & Superior & Muy superior \\
\hline Total población & 160 & 1750 & 1720 & 235 & 834 \\
\hline \multicolumn{6}{|l|}{$\begin{array}{l}\text { Perfil docente } \\
\text { (español) }\end{array}$} \\
\hline Género & Femenino & Femenino & Femenino & Masculino & Femenino \\
\hline Edad & 45 años & 58 años & 48 años & 53 años & 37 años \\
\hline $\begin{array}{l}\text { Formación académica } \\
\text { (pregrado) }\end{array}$ & $\begin{array}{l}\text { Estudios de } \\
\text { fonoaudiología } \\
\text { y Terapia del } \\
\text { lenguaje } \\
\text { (6 semestres) }\end{array}$ & $\begin{array}{l}\text { Lic. en básica } \\
\text { primaria }\end{array}$ & $\begin{array}{l}\text { Lic. en básica } \\
\text { primaria }\end{array}$ & $\begin{array}{l}\text { Lic. en básica } \\
\text { primaria }\end{array}$ & $\begin{array}{l}\text { Lic. en } \\
\text { educación } \\
\text { español- } \\
\text { matemáticas }\end{array}$ \\
\hline $\begin{array}{l}\text { Formación académica } \\
\text { (posgrado) }\end{array}$ & Ninguna & Ninguna & Ninguna & Ninguna & $\begin{array}{l}\text { Especialización } \\
\text { en matemáticas }\end{array}$ \\
\hline
\end{tabular}




\begin{tabular}{|c|c|c|c|c|c|}
\hline & Colegio 01 & Colegio 02 & Colegio 03 & Colegio 04 & Colegio 05 \\
\hline $\begin{array}{l}\text { Años de experiencia } \\
\text { docente }\end{array}$ & 18 años & 30 años & 25 años & 30 años & 12 años \\
\hline $\begin{array}{l}\text { Años de experiencia } \\
\text { enseñando español }\end{array}$ & 1 año & 30 años & 1 año & 8 años & 1 año \\
\hline $\begin{array}{l}\text { Cantidad de colegios } \\
\text { en que ha laborado }\end{array}$ & 3 & 2 & 8 & 4 & 3 \\
\hline $\begin{array}{l}\text { Número de horas que } \\
\text { labora a la semana }\end{array}$ & 40 & 40 & 26 & 30 & 35 \\
\hline $\begin{array}{l}\text { Número de horas de } \\
\text { contacto (clase) }\end{array}$ & 30 & 24 & 26 & 25 & 33 \\
\hline $\begin{array}{l}\text { Número de horas para } \\
\text { planeación/evaluación }\end{array}$ & 10 & 16 & 8 & 5 & 1 \\
\hline Asignación salarial & 1.300 .000 & 4.300 .000 & 1.350 .000 & 2.100 .000 & 1.500 .000 \\
\hline Incentivos & $\begin{array}{l}\text { Detalle día del } \\
\text { maestro }\end{array}$ & $\begin{array}{l}\text { Capacitacio- } \\
\text { nes y talleres }\end{array}$ & $\begin{array}{l}\text { Capacitacio- } \\
\text { nes y detalle } \\
\text { (día del } \\
\text { maestro) }\end{array}$ & $\begin{array}{l}\text { Capacitacio- } \\
\text { nes y talleres }\end{array}$ & $\begin{array}{l}\text { Capacitación } \\
\text { y asistencia a } \\
\text { congresos }\end{array}$ \\
\hline Otros & & $\begin{array}{l}1 \text { salario más } \\
\text { al año }\end{array}$ & $\begin{array}{l}\text { Recono- } \\
\text { cimiento } \\
\text { a la labor } \\
\text { realizada en } \\
\text { general } \\
\end{array}$ & & \\
\hline \multicolumn{6}{|l|}{$\begin{array}{l}\text { Perfil } \\
\text { población } \\
\text { grado quinto }\end{array}$} \\
\hline Promedio de edad & 11 años & 11 años & 11 años & 10 años & 11 años \\
\hline $\begin{array}{l}\text { Cantidad de } \\
\text { estudiantes por nivel }\end{array}$ & 24 & 120 & 130 & 96 & 56 \\
\hline $\begin{array}{l}\text { Cantidad de } \\
\text { estudiantes por curso }\end{array}$ & 24 & 25 & 32 & 32 & 28 \\
\hline Cantidad de cursos & 1 & 5 & 4 & 3 & 2 \\
\hline $\begin{array}{l}\text { Cantidad de } \\
\text { estudiantes hombres }\end{array}$ & 15 & 12 & 4 & 42 & 0 \\
\hline $\begin{array}{l}\text { Cantidad de } \\
\text { estudiantes mujeres }\end{array}$ & 9 & 13 & 126 & 54 & 56 \\
\hline $\begin{array}{l}\text { Cantidad de } \\
\text { estudiantes con una } \\
\text { condición especial }\end{array}$ & 0 & 0 & 0 & 7 & 0 \\
\hline $\begin{array}{l}\text { Cantidad de horas clase } \\
\text { español a la semana }\end{array}$ & 6 & 6 & 6 & 4 & 5 \\
\hline
\end{tabular}

Fuente: elaboración propia 


\section{Análisis de los perfiles de los docentes observados}

El siguiente cuadro destaca los aspectos relevantes de los perfiles docentes que podrían asociarse con el proceso de desarrollo de competencias escriturales.

Tabla 3. Análisis de los perfiles de los docentes

\begin{tabular}{|l|l|l|l|l|l|}
\hline & Colegio 01 & Colegio 02 & Colegio 03 & Colegio 04 & \multicolumn{1}{|c|}{ Colegio 05 } \\
\hline $\begin{array}{l}\text { Formación académica } \\
\text { (pregrado) }\end{array}$ & $\begin{array}{l}\text { Estudios de } \\
\text { terapia del } \\
\text { lenguaje } \\
(6 \text { semestres) }\end{array}$ & $\begin{array}{l}\text { Lic. en } \\
\text { básica } \\
\text { primaria }\end{array}$ & $\begin{array}{l}\text { Lic. en } \\
\text { básica } \\
\text { primaria }\end{array}$ & $\begin{array}{l}\text { Lic. en básica } \\
\text { primaria }\end{array}$ & $\begin{array}{l}\text { Lic. en básica } \\
\text { primaria español } \\
\text { - matemáticas }\end{array}$ \\
\hline $\begin{array}{l}\text { Formación académica } \\
\text { (postgrado) }\end{array}$ & Ninguna & Ninguna & Ninguna & Ninguna & $\begin{array}{l}\text { Especialización } \\
\text { en matemáticas }\end{array}$ \\
\hline $\begin{array}{l}\text { Años de experiencia } \\
\text { docente }\end{array}$ & 18 años & 30 años & 25 años & 30 años & 12 años \\
\hline $\begin{array}{l}\text { Años de experiencia } \\
\text { enseñando español }\end{array}$ & 1 año & 30 años & 10 años & 8 año & 1 año \\
\hline $\begin{array}{l}\text { Número de horas para } \\
\text { planeación /evaluación }\end{array}$ & 10 & 16 & 8 & 5 & 1 \\
\hline Asignación salarial & 1.300 .000 & 4.300 .000 & 1.350 .000 & 2.100 .000 & 1.500 .000 \\
\hline
\end{tabular}

Fuente: elaboración propia

El cuadro anterior resulta revelador en los aspectos que destacamos a continuación: excepto la docente del colegio 01, los demás docentes tienen una formación de pregrado que contempla la formación pedagógica y la aproximación a la enseñanza de la lengua, en tanto que su título es en licenciatura en básica primaria. Cabe destacar que ninguno de los docentes tiene una formación disciplinar especializada en la enseñanza de lengua castellana; en ese mismo sentido, solo hay una docente que tiene un título de posgrado y este no tiene que ver tampoco con la enseñanza de lengua castellana.

Hay diferencias significativas en cuanto a la experiencia docente, no solo en los años de quehacer, sino, y particularmente, en la enseñanza de la lengua materna: la profesora del colegio 02 tiene 30 años de experiencia enseñando la materia y el profesor del colegio 048 años, frente a un año de los profesores de los colegios 01, 04 y 05. Cabe destacar a este respecto que, independientemente de la diferencia en años de experiencia entre los docentes observados, los resultados alcanzados por los estudiantes de los docentes de los colegios 02 y 04 tampoco dieron cuenta de que dicha diferencia contribuyera en el desarrollo de competencias escriturales en sus estudiantes.

Es importante anotar, también, que hay condiciones extrínsecas que sin duda inciden en el desempeño de los docentes y que no podemos desconocer; es el caso de las horas de planeación que los diferentes colegios proveen a los docentes, la asignación salarial y las condiciones contractuales. Como lo muestra el cuadro anterior, se revelan también diferencias considerables que nos obligan a focalizar la atención en la docente del colegio 02, particularmente, en cuanto estas resultan favorables: un buen salario y horas razonables de clase que le dejan tiempo considerable para la planeación; no obstante, estas variables tampoco incidieron en el desarrollo de las competencias escriturales de sus estudiantes, como lo muestra el análisis realizado. 
Tomando en consideración los aspectos descritos, llama la atención que independientemente de la formación disciplinar, la experiencia que se tenga o las condiciones laborales, más o menos favorables para algunos de los docentes observados, el resultado alcanzado por los estudiantes en el desarrollo de sus competencias en escritura es indistintamente insatisfactorio.

\section{Conclusiones}

Esta investigación se enfocó en hacer evidente de qué forma las competencias disciplinares y pedagógicas de cinco docentes de lengua castellana de quinto grado de primaria incidieron en el desarrollo de los procesos escriturales de sus estudiantes; estos fueron nuestros hallazgos.

La labor realizada por los cinco docentes de lengua castellana observados en su ejercicio de guiar y contribuir en el desarrollo de competencias en escritura no redundó en frutos significativos. Los docentes impartieron una enseñanza mecánica y aislada que se verificó en la aplicación y reproducción de conceptos desarticulados que no tenían un norte claro; en consecuencia, las producciones escritas que se propusieron no pasaron de ser simples actividades, que no se plantearon como parte del desarrollo de un proceso de escritura planificado. A pesar de que el imaginario en torno a la enseñanza de la lengua materna le confiere un valor fundamental al proceso de escritura, este en la realidad observada no dio cuenta de ello.

En relación con lo disciplinar, es evidente, por un lado, que en cada una de las categorías analizadas para dar cuenta de esta competencia, los docentes observados no cumplieron con unos mínimos esperados y requeridos, de entrada esbozados en el documento rector del área: los Estándares Básicos para las Competencias en Lenguaje. En todas las categorías, el análisis se sintetiza en valoraciones del tipo: no se realizó, el alcance fue muy limitado, el abordaje fue básico, elemental, no hay evidencia, se hizo un intento, etc. Así, entonces, podemos cotejar esto con lo encontrado en el análisis de los perfiles de los docentes. La enseñanza del proceso de escritura está orientada por docentes con formación pedagógica en cuatro de los casos, pero no disciplinar como fundamento; los mismos cuatro docentes son licenciados en básica primaria, lo que supondría tener una formación mínima y decorosa en torno a los saberes disciplinares propios de este nivel educativo; no obstante, por lo observado en las planeaciones de clase, en los cuadernos de los estudiantes y en los diferentes trabajos de producción escrita propuestos, no hay evidencia del saber erudito del que habla Camilloni (2007), pues no se constata en las estrategias pedagógicas y didácticas desplegadas en los mismos que los profesores manejen teorías y sean capaces de transmitirlas a sus estudiantes con el ánimo de incidir en el desarrollo de sus procesos de escritura. Seguramente, estos docentes están enseñando como aprendieron, y continúan perpetuando, en consecuencia, unas prácticas de las que fuimos víctimas muchos de nosotros y que en un momento determinado de nuestra formación académica o de nuestra vida laboral nos confrontaron con una realidad: tampoco sabíamos escribir cuando llegamos a la universidad.

Se infiere, entonces, que si no se tiene la formación disciplinar, la pedagógica no es suficiente para lograr los objetivos que se propongan, así como tampoco las condiciones laborales o contractuales bajo las que ejercen los docentes. Variables extrínsecas del problema, que sin duda son también importantes, no tuvieron ninguna injerencia en el resultado observado y que está relacionado con el perfil docente.

En cuanto a las competencias pedagógicas asociadas con el desarrollo del proceso de escritura, se observó que las diferentes 
actividades de producción escrita planteadas por los profesores no eran claras, ni creativas; adicionalmente, muchas de ellas eran repetitivas y no retaban a los estudiantes; en definitiva, no promovían el desarrollo de competencias escritoras. La mayoría de las veces se recurrió solo a transcripciones, por ejemplo, de cuentos, leyendas o mitos, o se pidió escribir oraciones con los verbos, adjetivos o temas vistos en una clase en particular. $\mathrm{Al}$ respecto, cabe mencionar que muchos ejercicios que privilegiaban lo gramatical proponían oraciones ideales, no producto de situaciones comunicativas reales, que es lo que sugieren estándares cuando hablan del abordaje del nivel pragmático de la lengua. Es importante destacar que el ejercicio de escritura más trabajado en los colegios fue el resumen: en todos fue asumido o abordado como un ejercicio de escritura automática, espontánea, que, al parecer, no entraña características textuales o discursivas específicas y tampoco necesita de un proceso.

A través de los instrumentos analizados: planeaciones de clase, cuadernos de los estudiantes y trabajos de producción escrita, se constató que los docentes del área de lengua castellana de los colegios observados no dieron cuenta de competencias pedagógicas que promovieran el desarrollo de las competencias de escritura en sus estudiantes, puesto que en ninguna de las muestras analizadas se hizo evidente una intención, ni explícita ni implícita, de desarrollar este tipo de competencias; no hubo un solo ejercicio escritural juicioso y riguroso que mostrara el desarrollo de un proceso por parte de los docentes. De igual manera, en relación con la retroalimentación, cuando hubo un ejercicio de producción escrita que propusiera o incitara a escribir, esta resultó precaria o nula, lo que no permitió, tampoco, el avance en el desarrollo de las competencias escriturales.

Así, entonces, en tanto no hay evidencia de que los docentes dieran cuenta de competencias
Si el docente dejara de lado el afán por el cumplimiento de unos temas

o contenidos y se concentrara en el desarrollo de competencias, el resultado alcanzado sería otro, sin duda mejor.

disciplinares y pedagógicas fuertes, los bajos niveles de desempeño alcanzados por los estudiantes son la consecuencia lógica de estas falencias. En los diferentes trabajos escritos analizados se observaron, además, de manera contundente, serios problemas de redacción, léxico limitado, estilo oralizado y ausencia de mecanismos de cohesión, propios del texto escrito; asimismo, la promoción de la creatividad resultó insuficiente.

Teniendo en cuenta lo anterior, se hace necesario que los docentes de lengua castellana que tienen la responsabilidad de guiar y acompañar el desarrollo de competencias de lectura y escritura tomen conciencia del rol fundamental que desempeñan en este proceso. Como se vislumbra el panorama a partir de la muestra analizada, los docentes de lengua no están haciendo lo suficiente para que sus estudiantes alcancen unos niveles de desempeño, decorosos en sus producciones escritas.

En consecuencia, es imperioso que los profesores de lengua castellana sean reflexivos acerca de su práctica diaria y asuman con rigor la responsabilidad que les asiste, lo que implica comprender e interpretar el proceso de enseñanza-aprendizaje en el contexto que les corresponde, valiéndose del diagnóstico, la planificación y la evaluación rigurosa del proceso escritural; de tal suerte que estaríamos dando un paso significativo en la consecución de estándares más altos y más dignos, en concordancia con una sociedad que requiere que sepamos hacer en contexto. 
Si el docente dejara de lado el afán por el cumplimiento de unos temas o contenidos y se concentrara en el desarrollo de competencias, el resultado alcanzado sería otro, sin duda mejor. Esto implica moverse del paradigma contenidista que ha imperado en nuestra educación, al paradigma del desarrollo de competencias; una tarea de hecho más demandante, pero que redundaría en estudiantes reflexivos y críticos, capaces de expresar ideas claras y contundentes en sus producciones escritas, los que requiere nuestra realidad: la de un país ad portas del posconflicto.

\section{Referencias}

Camiloni, A. W. (2007). El saber didáctico. Buenos Aires: Paidós.

Cassany, D. (1989). Describir el escribir. Barcelona: Paidós.

Cassany, D. (1999). Construir la escritura. Madrid: Paidós.

Flower, L. \& Hayes, J. (1996). La teoría de la redacción como proceso cognitivo. En L. Flower, \& J. Hayes, Textos y contextos. Obtenido de http://media.utp.edu.co/referen cias-bibliográficas/uploads/referencias/ libro/518-flowers-y-hayes-la-teoria-de-la-re daccion-como-proceso-cognitivopdf-xwyX0articulo.pdf
Flórez, R. (1995). Hacía una pedagogía del Conocimiento. McGraw Hill. Santafé de Bogotá.

MEN (2006). Estándares básicos de competencias en lenguaje, matemáticas, ciencias y ciudadanas. Bogotá, Ministerio de Educación Nacional (Editor).

Van Dijk, T. (1996). Estructuras y funciones del discurso. México, Siglo Veintiuno.

Zubiría, J. D. (2006). Los modelos pedagógicos. Hacia una pedagogía dialogante. Bogotá: Magisterio. 